\title{
30 years of Katayama's article on ionic and non-ionic contrast media: appreciation of well and less known facts of a milestone paper
}

\author{
Ingrid B. Böhm \\ Department of Diagnostic, Interventional, and Pediatric Radiology, Inselspital, University of Bern, Bern, Switzerland \\ Correspondence to: Dr. Ingrid B. Böhm, MD. Department of Diagnostic, Interventional and Pediatric Radiology, Inselspital, University of Bern, \\ Freiburgstrasse 10, CH-3010 Bern, Switzerland. Email: ingrid.boehm@insel.ch.
}

Submitted Jul 06, 2020. Accepted for publication Jul 19, 2020.

doi: 10.21037/qims-20-843

View this article at: http://dx.doi.org/10.21037/qims-20-843

The corona virus COVID19/SARS-Co2 controls worldwide life in all its facets as well as the topics of medical publications. Nevertheless, there are still other topics. We should regard other topics even in these Corona times, too. Therefore, the goal of this comment is to celebrate a historical event. Which event? 125 years ago, Wilhelm Conrad Roentgen discovered the so-called X-rays. Indeed, for radiologists an important event, but Mr. Roentgen is not the one I will congratulate. Another milestone in radiology is the original paper by Hitoshi Katayama and colleagues (1) published 30 years ago. This famous work is the focus of the comment.

The Katayama-paper (1) is a classic and currently, the most cited contrast medium (CM) paper. As to whether Hitoshi Katayama realized this while writing his manuscript or shortly following its publication? I guess, not at all. It was the correct paper at the correct moment. Already in 1990, Katayama recognized the value of the upcoming nonionic ICMs. In 1990, non-ionic ICMs were approved for clinical use, but most radiologists still preferred ionic ICMs. Today, we can no longer imagine that. 30 years ago, the world was quite different, and the use of non-ionic ICMs was the exception not the rule. Courage and an outstanding study were necessary to defy established structures. Katayama had both, and the results of his paper speak for themselves: 21,428 (12.66\%) adverse drug reactions (ADRs) following the application of ionic and 5,276 (3.13\%) ADRs following the application of non-ionic ICMs (1). Thereby, Katayama and colleagues clearly showed the significant better tolerability of non-ionic iodinated contrast media
(ICMs) as compared to formerly established ionic ICMs (1). This central finding has been cited 1,758 times (according to google scholar on 2020 May $19^{\text {th }}$ ). Shortly following the publication, the acceptance of Katayama's paper was low. A representative proportion of radiologists tried to hold on ionic contrast agents. How should one question the outstanding results by Katayama et al.? For example, the article by Hamilton asserts that the better tolerability did not depend on the ICM used, but on the material of the seal of the ICMflask (2). He stated that, in the case of ionic ICMs, seals were made of natural rubber, whereas seals of flasks covering nonionic ICMs were made of artificial rubber (2). In other words, Hamilton suspected that $9.53 \%$ or 16,129 patients of the ionic ICM-group reacted against 2-mercaptobenzothiazole. Could this be true? The answer is simply: not at all. We can invalidate this hypothesis quickly. Even if the seals were made of different materials, the conclusion is incorrect, because the low incidence of patients with allergy against natural rubber or 2-mercaptobenzothiazole (3) cannot explain the obtained difference.

Are there further interesting aspects concerning the Katayama paper that are less known? I think so. Two examples are given.

(I) Documentation of the exact contrast medium name is today the exception rather than the rule (4). Already in 1990, Katayama's case record form used for the survey (figure 1 of Katayama et al.'s paper) listed the name of contrast medium used (1). Thereby, the paper by Katayama et al. is a trendsetter not only with respect to the use of non-ionic ICMs. 
(II) The central topic of the work by Katayama et al. is the comparison of ionic and non-ionic ICMs with respect of their tolerability (1). Importantly, by changing ionicity or osmolarity the authors also changed the chemical structure of the ICM. Table 4 of Katayama et al.'s paper shows that patients with a history of both exposure to contrast media, and ICM-related ADR had a significant higher prevalence rate when receiving ionic than receiving non-ionic ICMs (44.04\% vs. 11.24\%) (1). Although Katayama did not investigate the type of ICM with regard to the history of ADRs, most ADRs could be related to ionic ICMs, because non-ionic contrast media were introduced in Japan recently before performing the study (1). Now changing the ICM molecule is an established prophylaxis in patients with a history of an ICM-hypersensitivity $(5,6)$. Interestingly, Katayama et al. provided a hint for this assumption already in 1990 (1).

\section{What has changed during the last $\mathbf{3 0}$ years?}

Today, non-ionic ICMs are established agents; 30 years ago, this was not the case. The paper of Katayama is a milestone. The paper marks the beginning of a new era in radiology, the era of non-ionic ICMs, and thereby the era of increased ICM safety.

\section{What remained unchanged during the last 30 years?}

Scepticism against new, innovative ideas persists. Even 30 years following its publication, there are still important points that have not been included in clinical routine practice. For example, the necessary documentation of the name of the contrast medium used is missing in most patient records (4). 30 years following the publication of Katayama's classic work, it was time for a change with respect of this kind of practice.

The paper by Katayama et al. (1) is a milestone, and even 30 years after its publication, it is an interesting reading. Congratulation!

\section{Acknowledgments}

Funding: None.

\section{Footnote}

Conflicts of Interest: The author has completed the ICMJE uniform disclosure form (available at http://dx.doi. org/10.21037/qims-20-843). The author has no conflicts of interest to declare.

Open Access Statement: This is an Open Access article distributed in accordance with the Creative Commons Attribution-NonCommercial-NoDerivs 4.0 International License (CC BY-NC-ND 4.0), which permits the noncommercial replication and distribution of the article with the strict proviso that no changes or edits are made and the original work is properly cited (including links to both the formal publication through the relevant DOI and the license). See: https://creativecommons.org/licenses/by-nc-nd/4.0/.

\section{References}

1. Katayama H, Yamaguchi K, Kozuka T, Takashima T, Seez $\mathrm{P}$, Matsuura K. Adverse reactions to ionic and nonionic contrast media. A report from the Japanese Committee on the Safety of Contrast Media. Radiology 1990;175:621-8.

2. Hamilton G. Medical Rubber Anaphylaxis. Lancet 1990;336:1453-4.

3. Warshaw EM, Raju SI, Mathias CG, DeKoven JG, Belsito DV, Maibach HI, Taylor JS, Sasseville D, Zug KA, Zirwas MJ, Fowler JF Jr, DeLeo VA, Marks JG Jr, Pratt MD, Storrs FJ. Concomitant patch test reactions to mercapto mix and mercaptobenzothiazole: retrospective analysis from the North American Contact Dermatitis Group, 1994-2008. Dermatitis 2013;24:321-7.

4. Böhm IB, van der Molen AJ. Recommendations for Standardized Documentation of Contrast MediumInduced Hypersensitivity. J Am Coll Radiol 2020;17:1027-8.

5. Böhm I, Nairz K, Morelli JN, Keller PS, Heverhagen JT. Iodinated Contrast Media and the Alleged "Iodine Allergy": An Inexact Diagnosis Leading to Inferior Radiologic Management and Adverse Drug Reactions. Rofo 2017;189:326-32.

6. Böhm I, Medina J, Prieto P, Block W, Schild HH. Fixed drug eruption induced by an iodinated non-ionic $\mathrm{X}$-ray contrast medium: a practical approach to identify the causative agent and to prevent its recurrence. Eur Radiol 2007;17:485-9.

Cite this article as: Böhm IB. 30 years of Katayama's article on ionic and non-ionic contrast media: appreciation of well and less known facts of a milestone paper. Quant Imaging Med Surg 2020;10(12):2374-2375. doi: 10.21037/qims-20-843 